\title{
An interaction integral method for evaluating T-stress for two-dimensional crack problems using the extended radial point interpolation method
}

- Nguyen Thanh Nha

- Nguyen Thai Hien

- Nguyen Ngoc Minh

- Truong Tich Thien

Ho Chi Minh city University of Technology, VNU-HCM

(Manuscript Received on August 01 ${ }^{\text {st }}$, 2015, Manuscript Revised August 27 ${ }^{\text {th }}$, 2015)

\section{ABSTRACT:}

The so-called T-stress, or second term of the William (1957) series expansion for linear elastic crack-tip fields, has found many uses in fracture mechanics applications. In this paper, an interaction integral method for calculating the T-stress for two-dimensional crack problems using the extended radial point interpolation method (XRPIM) is presented. Typical advantages of RPIM shape function are the satisfactions of the Kronecker's delta property and the high-order continuity. The T-stress can be calculated directly from a path independent interaction integral entirely based on the J-integral by simply the auxiliary field. Several benchmark examples in $2 D$ crack problem are performed and compared with other existing solutions to illustrate the correction of the presented approach.

Key words: T-stress, stress intensity factors, meshless, RPIM

\section{INTRODUCTION}

The fracture behavior of cracked structures is dominated mainly by the near-tip stress field. In linear-elastic fracture mechanics interest is focused mostly on stress intensity factors (SIFs) which describe the singular stress field ahead of a crack tip and govern fracture of a specimen when a critical stress intensity factor is reached. The usefulness of crack tip parameters representing the singular stress field was shown very early by numerous investigations. Nevertheless, there is experimental evidence that also the stress contributions acting over a longer distance from the crack tip may affect fracture mechanics properties [1,2]. The constant stress contribution (first "higher-order" term of the Williams stress expansion, denoted as the T-stress term [3]) is the next important parameter. Several researchers $[4$, 5, 6 and 7] have shown that the T-stress, in addition to the $\mathrm{K}$ or $\mathrm{J}$-integral, provides an effective two-parameter characterization of plane strain elastic crack-tip fields in a variety of crack configurations and loading conditions. In special cases, the T-stress may be advantageous to know also higher coefficients of the stress series expansion. In order to calculate the T-stress, researchers have used several techniques such as 
the stress substitution method [1], the variational method [8], the Eshelby J-integral method [9], the Betti-Rayleigh reciprocal theorem $[10,11]$ and the interaction integral method [10, 12]. Among these method, the last three method are based on path-independent integral and the T-Stress can be caculated using data remote from crack-tip, so the result is achieved higher accuracy compared to the other method.

For a few idealized cases, analytical solutions for T-stress are available. However, for practical problems involving finite geometries with complex loading, numerical methods need to be employed. Chuin-Shan Chen et al (2001) applied a p-version finite element method to compute the T-stress [10]. In 2003, Glaucio H. Paulino and Jeong-Ho Kim presented a new approach to compute the $\mathrm{T}$-stress in funtionally graded materials (FGMs) based on the interaction integral method, in combination with the finite element method [13]. In 2004, Alok Sutradhar and Glaucio H. Paulino used Symmetric Galerkin boundary element method (SBEM) for calculating T-stress and SIFs [14].

During the past two decades, the so-called meshless or meshfree methods have developed, and their applications in solving many engineering problems have proved their applicability. Different from FEM, meshfree methods do not require a mesh connect data points of the simulation domain. Since no finite mesh is required in the approximation, meshfree methods are very suitable for analyzing crack problems [15, 16, 17, 18].

In this study, we propose an extended meshfree method based on the radial point interpolation method (XRPIM) associated with the vector level set method for evaluating $\mathrm{T}$-stress for two-dimensional crack problems. To calculate the T-stress, the interaction integral formulation for homogeneous materials is used. Several numerical examples T-stress calculation are performed and investigated to highlight the accuracy of the proposed method.

\section{XRPIM FORMULATION FOR CRACK PROBLEMS}

\subsection{Weak-form formulation}

Consider a 2D solid with domain $\Omega$ and bounded by $\Gamma$, the initial crack face is denoted by boundary $\Gamma_{c}$, the body is subjected to a body force $\mathbf{b}$ and traction $\overline{\mathbf{t}}$ on $\Gamma_{t}$ as depicted in Fig. 1. If the crack faces are assumed to be tractionfree, the weak-form obtained for this elastostatic problem can be written as

$\int_{\Omega} \delta \boldsymbol{\varepsilon}^{T} \boldsymbol{\sigma} d \Omega-\int_{\Omega} \delta \mathbf{u}^{T} \mathbf{b} d \Omega-\int_{\Gamma_{t}} \delta \mathbf{u}^{T} \overline{\mathbf{t}} d \Gamma=0$

where $\mathbf{u}$ are the vectors of displacements, $\boldsymbol{\sigma}$ and $\boldsymbol{\varepsilon}$ are stress and strain tensors, respectively. These unknowns are functions of location and time: $\mathbf{u}=\mathbf{u}(\mathbf{x}, t), \quad \boldsymbol{\sigma}=\boldsymbol{\sigma}(\mathbf{x}, t)$ and $\boldsymbol{\varepsilon}=\boldsymbol{\varepsilon}(\mathbf{x}, t)$.

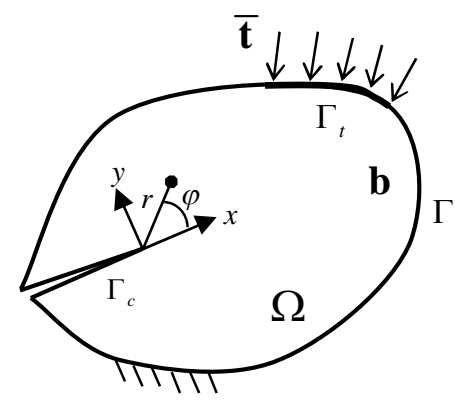

Figure 1. A 2D crack model

\subsection{Meshless X-RPIM discretization and vector level set method}

Base on the extrinsic enrichment technique, the displacement approximation is rewritten in terms of the signed distance function $\mathrm{f}$ and the distance from the crack tip as follow:

$$
\begin{aligned}
& u^{h}(\mathbf{x}, t)=\sum_{I \in W(\mathbf{x})} \phi_{I}(\mathbf{x}) u_{I}+\sum_{I \in W_{b}(\mathbf{x})} \phi_{I}(\mathbf{x}) \alpha_{I} H(f(\mathbf{x})) \\
& +\sum_{I \in W_{S}(\mathbf{x})} \phi_{I}(\mathbf{x}) \sum_{j=1}^{4} B_{j}(\mathbf{x}) \beta_{l j}
\end{aligned}
$$


where $\phi_{I}$ is the RPIM shape functions [19] and $f(\mathbf{x})$ is the signed distance from the crack line. The jump enrichment functions $H(f(\mathbf{x}))$ and the vector of branch enrichment functions $B_{j}(\mathbf{x})$ $(\mathrm{j}=1,2,3,4)$ are defined respectively by

$$
\begin{aligned}
& H(f(\mathbf{x}))=\left\{\begin{array}{lll}
+1 & \text { if } & f(\mathbf{x})>0 \\
-1 & \text { if } & f(\mathbf{x})<0
\end{array}\right. \\
& B(\mathbf{x})=\left(\sqrt{r} \sin \frac{\varphi}{2}, \sqrt{r} \cos \frac{\varphi}{2},\right. \\
& \left.\sqrt{r} \sin \frac{\varphi}{2} \sin \varphi, \sqrt{r} \cos \frac{\varphi}{2} \sin \varphi\right)
\end{aligned}
$$

where $r$ is the distance from $\mathrm{x}$ to the crack tip $\mathbf{x}_{T I P}$ and $\varphi$ is the angle between the tangent to the crack line and the segment $\mathbf{x}-\mathbf{x}_{T I P}$ as shown in Fig. 2. $W_{b}$ denotes the set of nodes whose support contains the point $\mathrm{x}$ and is bisected by the crack line and $W_{s}$ is the set of nodes whose support contains the point $\mathrm{x}$ and is slit by the crack line and contains the crack tip. $\alpha_{l}, \beta_{l j}$ are additional variables in the variational formulation.

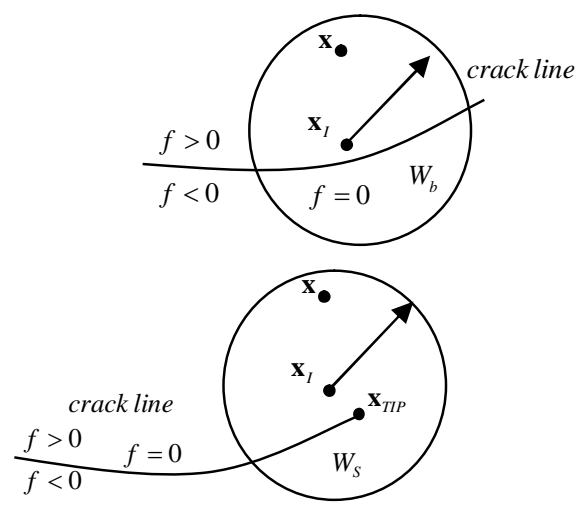

Figure 2. Sets of enriched nodes

\subsection{Discrete equations}

Substituting the approximation (2) into the well-known weak form for solid problem (1), using the meshless procedure, a linear system of equation can be written as

$$
\mathbf{K u}=\mathbf{F}
$$

with $\mathbf{K}$ being the stiffness matrices, respectively, and $\mathbf{F}$ being the vector of force, they can be defined by

$$
\begin{aligned}
& \mathbf{K}_{I J}=\int_{\Omega} \mathbf{B}_{I}^{T} \mathbf{D} \mathbf{B}_{J} d \Omega \\
& \mathbf{F}_{I}=\int_{\Omega} \boldsymbol{\Phi}_{I}^{T} \mathbf{b}_{I} d \Omega+\int_{\Gamma_{I}} \boldsymbol{\Phi}_{I}^{T} \overline{\mathbf{t}}_{I} d \Gamma
\end{aligned}
$$

where $\boldsymbol{\Phi}$ is the vector of enriched RPIM shape functions; the displacement gradient matrix B must be calculated appropriately dependent upon enriched or non-enriched nodes.

\section{THE INTERACTION INTEGRAL FOR T- STRESS IMPLEMENTATION}

\subsection{M-integral formulation}

The path-independent J-integral [20] is defined as

$$
J=\lim _{\Gamma \rightarrow 0} \int_{\Gamma}\left(W \delta_{1 j}-\sigma_{i j} u_{i, 1}\right) n_{j} d \Gamma,
$$

where $W$ is strain energy density given by

$$
W=\int_{0}^{\varepsilon_{k l}} \sigma_{i j} \varepsilon_{i j}
$$

and $n_{j}$ denotes the outward normal vector to the contour $\Gamma$.

After some mathematical transformations, the interaction integral can be written as

$$
\begin{aligned}
M & =\int_{\Gamma}\left\{\frac{1}{2}\left(\sigma_{i k} \varepsilon_{i k}^{a u x}+\sigma_{i k}^{a u x} \varepsilon_{i k}\right) \delta_{1 j}\right\} n_{j} d \Gamma \\
& -\int_{\Gamma}\left(\sigma_{i j} u_{i, 1}^{a u x}+\sigma_{i j}^{a u x} u_{i, 1}\right) n_{j} d \Gamma
\end{aligned}
$$

\subsection{Auxiliary fields for T-stress}

The auxiliary fields are judiciously chosen for the interaction integral depending on the nature of the problem to be solved. Since the Tstress is a constant stress that is parallel to the crack, the auxiliary stress and displacement fields are chosen due to a point force $f$ in the $x_{1}$ direction (locally), applied to the tip of a semiinfinite crack in an infinite homogeneous body, as shown in Fig. 3. 


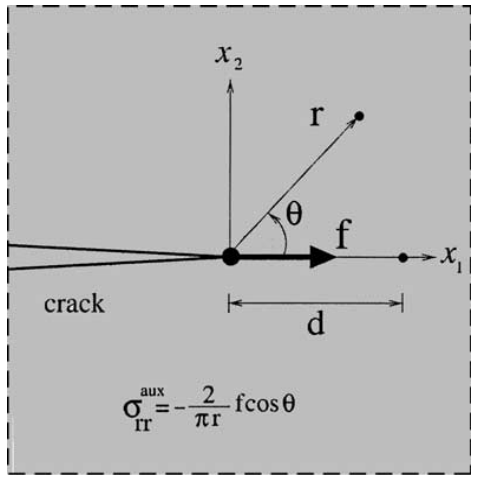

Figure 3. Auxiliary Field for T-stress: Michell's solution

The auxiliary stresses are given by Michell's solution [21]:

$$
\begin{aligned}
& \sigma_{11}^{a u x}=\frac{-f}{\pi r} \cos ^{3} \theta, \sigma_{22}^{a u x}=-\frac{f}{\pi r} \sin ^{2} \theta \\
& \sigma_{12}^{a u x}=\frac{-f}{\pi r} \cos ^{2} \theta \sin \theta
\end{aligned}
$$

The corresponding auxiliary displacements are [22]

$$
\begin{aligned}
& u_{1}^{a u x}=-\frac{f(1+\kappa)}{8 \pi \mu} \ln \frac{r}{d}-\frac{f}{4 \pi \mu} \sin ^{2} \theta \\
& u_{2}^{a u x}=-\frac{f(\kappa-1)}{8 \pi \mu} \theta+\frac{f}{4 \pi \mu} \sin \theta \cos \theta
\end{aligned}
$$

where $d$ is the coordinate of a fixed point on the $x_{1}$ axis, $\mu$ is the shear modulus, and

$$
\kappa= \begin{cases}(3-v) /(1+v) & \text { planestress } \\ (3-4 v) & \text { planestrain }\end{cases}
$$

\subsection{Determination of $\mathbf{T}$-stress}

By considering the auxiliary field in Eq. (11) , a simple expression for the T-stress in terms of the interaction integral $M$, the point force for the auxiliary field $f$, and material properties $E, v$ can be obtained.

$$
T=\frac{E^{\prime}}{f} M
$$

where
$E^{\prime}= \begin{cases}E & \text { planestress } \\ E /\left(1-v^{2}\right) & \text { plane strain }\end{cases}$

\section{NUMERICAL EXAMPLES}

\subsection{Edge crack plate under tensile loading}

In the first example, a rectangular plate with an edge crack is considered. The plate is subjected to a tensile stress $\sigma=1$ as shown in Fig. 4. The dimensions are set as $H / W=12$. Various values of crack length are chosen to investigate the static mode I SIF of the model. The plain strain state is assumed with elastic modulus $E=1$ and Poisson's ratio $v=0.3$. There are $16 \times 192$ scattered nodes are used for the problem. The coefficient of size of support domain is set as $\alpha_{d}=2.2$ and the length of $\mathrm{J}$ domain $l_{J}=a / 3$. The obtained results including normalized SIFs $\left(\overline{K_{I}}=K_{I} / \sigma \sqrt{\pi a}\right)$, normalized T-Stress $(\bar{T}=T / \sigma)$ and biaxiality ratio $\left(B=T \sqrt{\pi a} / K_{I}\right)$ are compared with Symmetric Galerkin boundary element method solution given by Sutradhar and Paulino [14], FEM solution given by Chuin-Shan Chen et al [10] and Feet T et al [23].

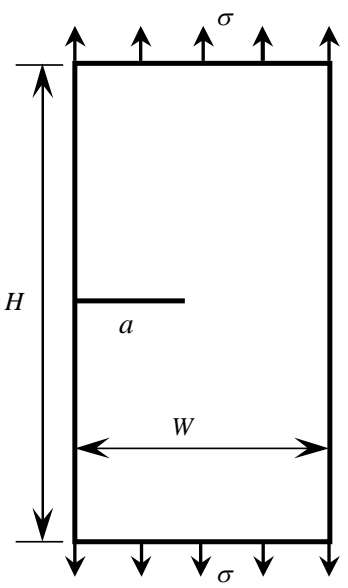

Figure 4. Edge crack plate under tensile loading

There are two crack length ratios are investigated $(a / W=0.3,0.5)$. Table 1 and Table 2 summerize the acceptable results 
obtained by XRPIM in the comparison with other solutions.

Table 1. Normalized T-Stress, SIFs and biaxiality ratio for edge crack plate $(a / W=0.3)$

\begin{tabular}{cccc}
\hline Method & $\bar{T}$ & $\overline{K_{I}}$ & $B$ \\
\hline $\begin{array}{c}\text { XRPIM } \\
\text { (proposed) }\end{array}$ & -0.6098 & 1.7419 & -0.3501 \\
$\begin{array}{c}\text { Analytical } \\
\text { [23] }\end{array}$ & -0.6141 & - & -0.3664 \\
$\begin{array}{c}\text { SGBEM } \\
{[14]}\end{array}$ & -0.6105 & 1.6597 & -0.3679 \\
FEM [10] & -0.6103 & 1.6598 & -0.3677 \\
\hline
\end{tabular}

Table 2. Normalized T-Stress, SIFs and biaxiality ratio for edge crack plate $(a / W=0.5)$

\begin{tabular}{cccc}
\hline Method & $\bar{T}$ & $\overline{K_{I}}$ & $B$ \\
\hline $\begin{array}{c}\text { XRPIM } \\
\text { (proposed) }\end{array}$ & -0.3998 & 2.8618 & -0.1397 \\
$\begin{array}{c}\text { Analytical } \\
\text { [23] }\end{array}$ & -0.4182 & - & -0.1481 \\
SGBEM & -0.4184 & 2.8241 & -0.1481 \\
{$[14]$} & & & \\
FEM [10] & -0.4217 & 2.8246 & -0.1493 \\
\hline
\end{tabular}

\subsection{Center crack plate under tensile loading}

The next example deals with a rectangular plate with a central crack as shown in Fig. 5. The dimensions are given as $H / W=1$ and $a / W=0.3$. The plate is subjected to a tensile load at the top and the bottom edges. The Young's modulus and the Poisson's ratio is similar to the previous example.

Because of the symmetry of geometry and load, a half model is consider with the symmetry boundary condition. A distribution of $25 \times 50$ nodes is used for the XRPIM model. Table 3 shows the comparison between the XRPIM results and other solutions with a good agreement.

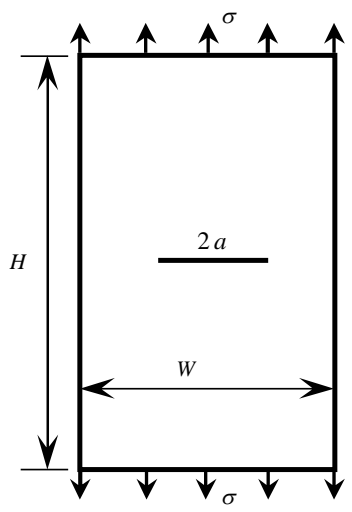

Figure 5. Rectangular plate with center crack under tensile loading

Table 3. Normalized T-Stress, SIFs and biaxiality ratio for edge crack plate $(a / W=0.3)$

\begin{tabular}{|c|c|c|c|}
\hline Method & $\bar{T}$ & $\overline{K_{I}}$ & $B$ \\
\hline $\begin{array}{c}\text { XRPIM } \\
\text { (proposed) }\end{array}$ & -1.1768 & 1.1663 & -1.0090 \\
\hline $\begin{array}{c}\text { Analytical } \\
{[23]}\end{array}$ & -1.1557 & - & -1.0279 \\
\hline $\begin{array}{c}\text { SGBEM } \\
{[14]}\end{array}$ & -1.1554 & 1.1232 & -1.0286 \\
\hline FEM [10] & -1.1554 & 1.1232 & -1.0286 \\
\hline
\end{tabular}

4.3. Inclined edge crack plate under tensile loading

In the last example, a plate with a slanted crack is considered. The plate is subjected to a uniform traction $\sigma=1$ at both top and bottom edges. The dimensions are $H=2 W=1$, the crack length is $a / W=0.4 \sqrt{2}$ and the incline angle is $\beta=45^{\circ}$. The Young's modulus is taken as $E=1$ and Poisson's ratio is set as $v=0.3$. 


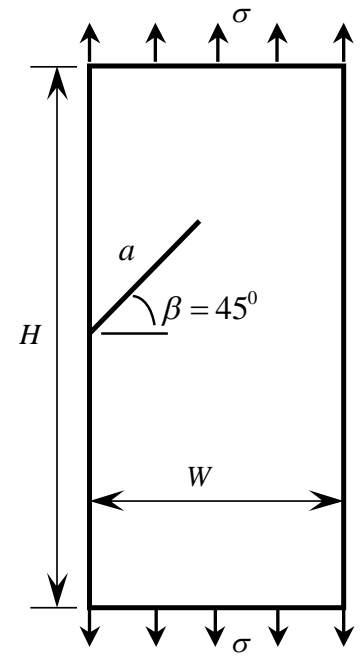

Figure 6. Inclined edge crack plate

This problem was solved by Kim and Paulino using FEM with interaction integral [24]. Moreover, Sutradhar and Paulino [14] used symmetric Galerkin boundary element method to get solution for this problem. In this work, the mixed mode values of normalized SIF and TStress are calculated using XRPIM to compare with available reference results as shown in Table 4 , which indicates good agreement.
Table 4. Normalized SIFs and T-Stress, for inclined edge crack plate

\begin{tabular}{|c|c|c|c|}
\hline Method & $K_{I} / \sqrt{\pi a}$ & $K_{I I} / \sqrt{\pi a}$ & $T$ \\
\hline $\begin{array}{c}\text { XRPIM } \\
\text { (proposed) }\end{array}$ & 1.471 & 0.568 & 0.727 \\
\hline $\begin{array}{c}\text { SGBEM } \\
{[14]}\end{array}$ & 1.446 & 0.615 & 0.775 \\
\hline FEM [13] & 1.446 & 0.615 & 0.764 \\
\hline
\end{tabular}

\section{CONSLUSION}

The interaction integral method applied to two-dimensional crack problems to evaluate Tstress using the XRPIM has been presented. Three numerical examples in which the T-stress are evaluated by means of the M-integral. The numerical results obtained are good agreement with known results from the references. The presented approach has shown several advantages and it is promising to be extended to more complicated problems such as computation $\mathrm{T}$ stress and SIFs, crack propagation problems in functionally graded materials. 


\section{Áp dụng tích phân tương tác tính toán T- Stress cho bài toán nứt hai chiều với phương pháp không lưới RPIM}

- Nguyễn Thanh Nhã

- Nguyễn Thái Hiền

- Nguyễn Ngọc Minh

- Trương Tích Thiện

Trường Đại học Bách khoa, ĐHQG-HCM

\section{TÓM TẮT:}

Thông số T-stress, còn gọi là số hạng thứ hai trong chuỗi khai triển của William cho các các trường đàn hồi tuyến tính ở lân cận đỉnh vết nứt, đóng vai trò quan trọng trong các bài toán cơ học nút. Trong báo cáo này, phương pháp tích phân tương tác được dùng kết hợp với phương pháp không lưới mở rộng dựa trên phép nội suy điểm hướng kính (XRPIM) được dùng để tính toán thông số T-stress. Hàm dạng RPIM được chọn vì có các ưu điểm như thỏa mãn

thuộc tính Kronecker's delta và liên tục bậc cao. Thông số T-stress được tính toán trực tiếp từ tích phân tương tác được chiết xuất từ tích phân độc lập đường đi $\mathrm{J}$, kết hợp với các miền phụ trợ cho T-stress. Một số bài toán nứt phẳng được tính toán và kiểm chứng kết quả với lời giải tham khảo từ các phương pháp khác. Sự phù hợp giữa các kết quả thể hiện tính chính xác của phương pháp được chọn.

Từ khóa: vật liệu FGM, hệ số cường độ ứng suất, phương pháp không lưới RPIM

\section{REFERENCES}

[1]. Larsson SG, Carlson AJ. Influence of nonsingular stress terms and specimen geometry on small-scale yeilding at crack tips in elastic - plastic materials. J Mech Phys Solids 1973; 21, 263-277.

[2]. Sumpter JD. The effect of notch depth and orientation on the fracture toughness of multipass weldments. Int. J. Press. Ves. And Piping 1982; 10, 169 -180.

[3]. Williams ML. On the stress distribution at the base of a stationary crack. ASME Journal of Applied Mechanics 1957; 24, 109-114.
[4]. Du Z-Z, Hancock JW. The effect of nonsingular stresses on crack-tip constraint. J Mech Phys Solids 1991; 39(3), 555-567.

[5]. Du Z-Z, Betegon C and Hancock JW. J dominance in mixed mode loading. International Journal of Fracture 1991; 52, 191-206.

[6]. O'Dowd NP, Shih CF. Family of crack-tip fields characterized by a triaxiality parameter: Part I Structure of fields. Journal of the Mechanics and Physics of Solids 1991; 39, 989-1015

[7]. Wang YY. On the two-parameter characterization of elastic-plastic crack- 
front fields in surface-cracked plates. American Society for Testing and Materials 1993; 120-38.

[8]. Leevers PS, Radon JCD. Inherent stress biaxiality in various fracture specimen. Int $\mathbf{J}$ Fract 1982; 19(4), 311-325.

[9]. Kfouri AP. Some evaluations of the elastic T-term using Eshelby's method. Int J Fract 1986; 30(4) , 301-315.

[10]. Chen CS, Krause R, Pettit RG, Banks-Sills $\mathrm{L}$, Ingraffea AR. Numerical assessment of $T$ stress computation using a p-version finite element method. Int J Fract 2001; 107(2), 177-199.

[11].Sladek J, Sladek V, Fedelinski P. Contour integrals for mixed-mode crack analysis: effect of nonsingular terms. Theor Appl Fract Mech 1997; 27(2), 115-127.

[12].Nakamura T, Parks DM. Determination of T-stress along three three dimensional crack fronts using an interaction integral method. Int J Solids Struct 1992; 29(13), 1597-1611.

[13].Jeong-Ho Kim, Claucio H. Paulino. T-stress, mixed-mode stress intensity factors, and crack initiation angles in fucctionally graded materials: a unified approach using the interaction integral method. Comput. Methods Appl. Mech. Engrg. 2003; 192, 1463-1494.

[14].Alok Sutradhar, Glaucio H. Paulio. Symmetric Galerkin boundary element computation od T-stress and stress intensity factors for mixed-mode cracks by interaction integral method. Engineering analysis with Boundary Elements 2004; 28, 1335-1350.

[15].G. Ventura et al. A vector level set method and new discontinuity approximations for crack growth by EFG, International Journal for Numerical Methods in Engineering 2002; 54, 923-944.

[16].M. Fleming, Y. A. Chu, T. Belytschko. Enriched Element-Free Galerkin methods for crack tip fields, International Journal for Numerical Methods in Engineering 1997; 40, 1483-1504.

[17].P.H. Wen and M.H. Alibadi. Evaluation of mixed-mode stress intensity factors by the mesh-free Galerkin method: Static and dynamic. The Journal of Strain Analysis for Engineering Design 2009; 44, 273-286.

[18].Nguyen T.N., Bui T.Q., Zhang Ch., Truong T.T.. Crack growth modeling in elastic solids by the extended meshfree Galerkin radial point interpolation method. Engineering Analysis with Boundary Elements 2014; 44, 87-97.

[19].Liu G. R. - Mesh Free Methods 2003; Moving beyon the Finite Element Method. CRC Press LLC.

[20].Rice JR. Path-independent integral and the approximate analysis of strain concentration by notches and cracks. J Appl Mech Trans ASME 1968; 35(2), 379-386.

[21]. Michell JH. Elementary distributions of plane stress. Proc Lond Math Soc 1900; 32, 35-61.

[22]. Timoshenko SP, Goodier JN. Theory of elasticity, 3rd ed. New York, McGraw-Hill (1987).

[23].Fett T. T-stresses in rectangular plates and circular disks. Eng Fract Mech 1998; 60(56), 631-652.

[24].Jeong-Ho Kim, Claucio H. Paulino. Finite element evaluation of mixed-mode stress intensity factors in functionally graded materials. Int J Numer Meth Eng 2002; 53(8), pp. 1903-1935. 